\title{
Review of: "Transmission risk assessment of Aedes- borne arboviral diseases in Accra, Ghana"
}

\author{
Raja Babu Singh Kushwah
}

Potential competing interests: The author(s) declared that no potential competing interests exist.

Impressive work done in the field and the questions raised needs to addressed sooner than later. The role of Vitatus can be alarming too. High postivity of all the indices studied points toward the possibility of the explosion of these viral infections being the vector present in high densities. As scripted in article the antibodies against DENV2, shows an underlying transmission whihc need to pointed and surveliiance should be undertaken to keep this in check. As we all know the outbreaks can be serious when it comes to arboviruses. Nicely written article with results pointing out crucical scientific questions which are of high societal impact. 